\title{
Balancing prescription with teacher and pupil agency: Spaces for manoeuvre within a pedagogical model for working with adolescent girls
}

\author{
Kirk, D*\&., Lamb, CA*, Oliver, KL** with Ewing-Day, R^., Fleming, C.^, Loch, A.^ and \\ Smedley, V.^ \\ s*University of Strathclyde \\ \& University of Queensland \\ **New Mexico State University \\ ${ }^{\wedge}$ Glasgow City Council
}

\begin{abstract}
This paper explores the possibilities of using a pedagogical model for working with adolescent girls in physical education as a means of balancing the challenge of external prescription from outside the school with teacher and pupil agency. We report data from a study involving four schools in Glasgow. We note that the national curriculum for Scotland, Curriculum for Excellence, is a broad and bold type that provides teachers with 'spaces for manoeuvre' in order to shape local curricula that best meet the needs and interests of girls. This is particularly the case in physical education, which in the Basic General Education phase for 12-15 years olds there is no well-established assessment regime. We identify four spaces for manoeuvre for teachers and pupils within an activist model: new forms of communication based on authorising pupil voice; offering choices and opening up learning possibilities; the co-construction of a safe class environment; and opportunities to rethink traditional structures based on the multi-activity curriculum form. We conclude that an activist pedagogical model provided teachers and pupils with spaces to explore alternative practices to traditional forms of physical education.
\end{abstract}

Keywords: teacher and pupil agency; curriculum-making; pedagogical model; girls and physical education; spaces for manoeuvre

\section{Introduction}

An enduring challenge for innovation in education systems at least since the emergence of system-wide reforms in the 1950s has been the swinging pendulum of 'top-down' to 'bottomup' approaches (Macdonald, 2003). Discussing the 'axes of school reform' internationally, the OECD (2015) distinguish between types of curricula ranging from 'specific and less bold' to 'broad and bold'. Despite the variability these pendulum swings have generated, the trend in curriculum making since the 1980s in many systems has been towards 'broad and bold' designs such as 'guidelines', 'models' and 'frameworks', with associated 'strands' and 'learning areas' (UNESCO, 2013). While broad and bold approaches appear to provide teachers with space for participation in curriculum making, or in Priestley, Edwards, Miller \& Priestley's (2012) terms, 'spaces for manoeuvre', arguably, few have been able to adequately balance policy prescription particularly around specific pupil learning outcomes and teacher agency.

This is in part because the role that teachers and schools might play in curriculum making within 'national' curriculum reforms has remained largely unresolved. Priestley, Biesta and Robinson (2015) point out that teacher agency is a complex concept. They argue that it is not necessarily always positive and could provide teachers with opportunities to undermine change. Nor is it always clear to what extent agency is possible. Their ecological approach thus insists on the importance of asking 'agency for what (purpose)?', and highlights the 
importance of teachers working with the conditions and circumstances an environment provides. In secondary schools in particular, Priestley et al.'s (2012) research suggests that high stakes assessment can be a powerful determinant of what it is possible and even thinkable for teachers to do.

Physical education presents an interesting case in this respect. While high stakes examinations in physical education now feature in Scottish secondary schools, there has been little requirement until recently for physical education teachers to formally assess pupils' learning in the Basic General Education (BGE) phase (Thorburn \& Gray, 2010). This longstanding situation, where physical education teachers 'fly under the radar' of assessment as an accountability mechanism, arguably provides them with spaces for manoeuvre that teachers in other subject areas are mostly denied. Physical education is thus an interesting site to investigate approaches to curriculum making that involve partnerships between agents external to the school, including researchers, and teachers and pupils, particularly within a broad and bold curriculum type that is relatively non-prescriptive, such as Curriculum for Excellence (CfE) in Scotland (Priestley, 2010).

Since the 1960s in the UK, the traditional approach to programmes of physical education has been based on content. This traditional approach features short units of work drawing from games, aquatics, dance, gymnastics, athletics and outdoor activities. Physical education curriculum scholars have subjected this approach to sustained criticism for over two decades, in particular for a narrow and superficial focus on sport techniques, for failing to support learning progression, and for motivating only a small proportion of motorically-gifted pupils while dis-benefitting the rest, including large numbers of girls (e.g. Siedentop, 2002; Kirk, 2010; Oliver \& Kirk, 2015). Despite these critiques and the implementation of many curriculum initiatives, the multi-activity approach has retained a dominant position in school physical education programmes in the UK and internationally.

One response to these critiques is a long-standing literature in physical education on the use of curriculum (Jewett, Bain \& Ennis, 1995; Lund \& Tannehill, 2003) and instructional models (Metzler, 2011) as the 'organizing centre' for programmes, rather than content. More recently and building on this models-based approach to curriculum design, there has been increasing advocacy for school physical education programmes that consist entirely of pedagogical models (Casey, 2012). The term pedagogical model is preferred here since it more accurately than other terms represents the interdependency and interaction of curriculum, learning, teaching, and assessment (Kirk, 2013).

Adolescent girls are more likely than boys to disengage from school physical education (Oakley et al., 2017). First identified as 'a problem' in the early 1990s (Vertinsky, 1992), this situation has persisted despite many attempts throughout this 25 years period to find solutions (Kirk \& Oliver, 2014). Disengagement from school physical education has detrimental but avoidable social, economic and health consequences, particularly for girls growing up in areas of multiple deprivation (Scottish Health Survey, 2016). It is timely then that the situation of girls in physical education has been the topic of recent research in Scotland. Taylor, Hughes, \& Koufaki's (2013) evaluation of a community-based initiative called 'Girls on the Move' reported some positive though mainly mixed results in terms of maintaining Moderate to Vigorous Physical Activity over and beyond the six months intervention. Johnson, Gray, \& Horrell (2013) explored notions of girls' ideal bodies as potential barriers to their participation, while a range of environmental factors in school physical education, such as kit, changing rooms, and the presence of boys, have been identified by girls as 
barriers to participation (Niven, Henretty \& Fawkner, 2014). Mitchell, Inchley, Fleming \& Currie (2015) explored the formation of identities among girls in physical education, and discovered that girls identifying as 'non-sporty' were often intimidated by the presence in lessons of other girls they saw as 'sporty'. Mitchell, Gray \& Inchley (2015) reported that choice was a motivating factor for girls in a school-based physical activity programme. Relatedly, Thorburn \& Gray (2010) noted the initial positive influence of the inclusion of a wider range of non-competitive and traditional activities in the 'Fit for Girls' initiative that was first implemented in Scotland between 2008 and 2012. This recent research in Scotland confirms much of what is known about the situation of girls in other parts of the world, suggesting that these are global issues (Enright \& O'Sullivan, 2010; Oliver, Hamzeh \& McCaughtry, 2009).

The purpose of this paper is to provide an account of an approach to curriculum making that seeks to balance the contributions of researchers as agents external to the school, and teachers and pupils as local agents. We explain what pedagogical models in physical education are and provide an example of an activist model for working with adolescent girls. We briefly outline the research design and methods for this year-long intervention. We then provide some illustrations of spaces for manoeuvre for teachers and their pupils as they coconstructed their local physical education programmes based on an activist pedagogical model, with support from the research team. We conclude that a pedagogical models-based approach to physical education, within the broad and bold framework provided in this case by $\mathrm{CfE}$, does provide teachers and pupils with spaces for manoeuvre.

\section{Pedagogical models and curriculum-as-specification}

Stenhouse (1975, p.142) argued curriculum should not 'be regarded as an unqualified recommendation but rather a provisional specification claiming no more that to be worth putting to the test of practice'. Along with his notion of 'teacher-as-researcher', this idea of the curriculum-as-specification located teachers as part of a wider community of educational workers, including policy-makers, teacher educators and educational researchers working collaboratively and flexibly. He saw classrooms as 'educational laboratories' in which curriculum as a specification for practice invited critical testing rather than being a prescription for what teachers must do.

Consistent with Stenhouse's view of curriculum, pedagogical models are design specifications for the creation of programmes within schools that fit the local context. Pedagogical models are what Metzler (2011) calls 'the organising centre(s)' for physical education, in contrast to the multi-activity programme that takes content as its single organising principle. Pedagogical models consist of pupil learning outcomes or aspirations alongside teaching strategies, subject matter and assessment, as interrelated and interdependent components of pedagogy. Pedagogical models as design specifications seek to manage the tension between external (to the school) guidance and local agency, and the 'iron law of curriculum innovation', that 'the innovative idea will always and inevitably be transformed in the process of implementation' (Kirk \& Macdonald, 2001).

In traditional forms of practice in physical education, a wide range of physical, affective, cognitive and social learning outcomes are pursued through multi-activity programmes, in a kind of one-size-fits-all approach (Bailey et al., 2009). Pedagogical models, in contrast, are co-constructed to achieve particular pupil learning. All pedagogical models have the same broad components: a main idea, critical elements and learning outcomes or aspirations (Haerens, Kirk, Cardon, \& Bourdeauhuji, 2011). While researchers may typically identify 
these main components initially, their pedagogical model is only a prototype until it is tested in practice and co-constructed with the participation of teachers and pupils.

An example of this process is an activist model for working with adolescent girls in physical education. Oliver \& Kirk (2015) created the prototype model building on 20 years of activist research and practice by Oliver. The main idea of the model is to assist girls to learn to value the physically active life, an idea formulated initially by Siedentop (1996). A key word in this main idea is 'value', and an activist pedagogical model is specifically a 'pedagogy of affect', working primarily in the affective rather than the physical domain (Bailey et al., 2009). The model has four critical elements: student-centredness; pedagogies of embodiment; listening to respond over time; and inquiry-based learning centred in action. Along with the main idea, the critical elements make the model distinctive. During implementation of the prototype pedagogical model, these critical elements are 'non-negotiable'; they must be present in some form in a local curriculum, though teachers and pupils determine what they look like locally in detail. Finally, each model has learning outcomes or aspirations. The learning aspirations of an activist model are for girls to identify and name barriers to their physical activity enjoyment and participation. Girls also work with their teachers to negotiate and, if possible, transform the barriers within their control in order to increase their opportunities, interest and motivation for engaging in physical activity.

The content and teaching styles align tightly with these learning aspirations and are informed by the main idea and critical elements. We were able to draw on examples from Oliver's work, particularly her student-centred inquiry as curriculum approach within her activist programme (see Oliver \& Oestreirrch et al., 2015). At the same time, we did not know in advance of implementing the prototype model what content and teaching styles teachers might use, nor the needs and interests girls would identify as priorities for them. So, while the main idea and critical elements were 'non-negotiable', we expected teachers to use these to inform practice that was appropriate to their own local context of implementation. Before moving on to show how they did this, and the extent to which they and their pupils were able to identify and exploit spaces for manoeuvre, in the next section of the paper we outline briefly the study design and methods.

\section{Research design and methods}

We tested the prototype model with five teachers in four state schools in Glasgow over a school year, from September 2015 to June 2016. Each of the teachers had at least 10 years of experience teaching physical education, and three held promoted posts as heads of their respective departments or Faculties. All of the teachers apart from Cara Lamb (who had a dual role as researcher and teacher) chose their own pseudonyms, which are Jess, Kate, Laura and Liana. Our plan was to attempt a modest 'scaling-up' of Kim Oliver's activist practice, to learn whether other teachers could use an activist approach, with the prototype model to guide them. The teachers were recruited using snowball sampling (Noy, 2008), through local professional networks and word-of-mouth as well as an open workshop event attended by approximately 25 teachers and held in the Spring of 2015.

Three of the schools had between a third and a half of their pupils living in the most multiply deprived areas of Scotland as measured by the Scottish Index of Multiple Deprivation, while one school had over $80 \%$ of its children living in deciles $1-40$ postcodes (the most deprived). Two were denominational Catholic schools, one a girls-only school, and the other two were non-denominational and co-educational. The girls-only school had a multi-ethnic population and a high proportion of Muslim girls even though it was of Catholic denomination. The 
intervention classes varied in size, from 12 to 25 pupils, and were girls-only. Each teacher worked with one of their timetabled classes, which meant that one of the schools that had two teachers working there (Cara and another) had two different classes using the activist intervention. Physical education lessons were typically co-educational (except of course in the girls-only school), and the creation of girls-only classes for this project was a strategic decision made by the researchers and teachers together.

\section{Research design}

The study took the form of a 10 month-long intervention that had two phases. The first phase ran from September to December 2015 and was concerned with Building the Foundation (BfF) for an activist approach, details of which can be found in Kirk et al., (2016a). The second phase ran from January to June 2016 and involved the co-construction of a thematic unit of work in physical education. This second phase of the project is reported in Kirk et al., (2016b).

The five teacher-participants attended three one-day workshops led by Kim Oliver, in September 2015, January 2016 and May 2016. The workshops were both training sessions for the teachers in learning about an activist approach and also, in the January and May workshops, opportunities for data generation as they shared their experiences. In January and May 2016, Kim Oliver and Cara Lamb also conducted focus group interviews with girls involved in the research study classes, two classes from each school, involving approximately six to eight girls in each group. Teachers chose the participants, representing a range of interests and perceived competence in physical education. We carried out the focus group interviews in the schools, which allowed the researchers to become familiar with the physical sites for the intervention.

In addition, the teachers had an opportunity to share with each other examples of what they were doing with their classes through a closed social networking site as well as discuss issues and seek advice from all involved in the project. Some teachers, though not all, took this opportunity to share what they were doing and ask questions about how to deal with particular issues. Cara Lamb visited the schools around the half-way point of BtF and twice during the second phase between February and May, carrying out short interviews with each teacher in December 2015 and made notes of lessons she observed. Kim Oliver taught two sample lessons from BtF in the schools in September 2015. The January 2016 workshop involved collaboration between Kim and the teachers to develop a thematic unit the teachers would adapt, further develop and implement in phase two of the project.

\section{Data Generation Methods}

We used a range of data generation methods. All interviews and workshops (apart from the September 2015 workshop) were voice recorded and transcribed. David Kirk also made detailed hand written notes for all three workshops. Cara made written records of her lesson observations. The teachers wrote plans for their thematic units using a template developed with support from Kim and Cara. Cara, David and Kim had debrief conversations following each workshop, which were voice-recorded and transcribed. These conversations provided important and shared initial analyses of the themes that were emerging in each workshop.

\section{Findings and Discussion: The co-construction of a pedagogical model for working with adolescent girls: spaces for manoeuvre}

We commented in the introduction that physical education teachers have 'flown under the radar' of formal assessment in the BGE phase of Scottish schooling and that this situation has 
presented opportunities for local interpretation and implementation of the national CfE. This said, contributors to Thorburn's (2017) edited volume reveal a variable situation in which innovative practice sits alongside the obdurate status quo of traditional practice. We are interested, then, in the extent to which the teachers in this study were able to implement local programmes based on the prototype activist pedagogical model. In this section, we identify four 'spaces for manoeuvre' as they undertook this task in collaboration with their pupils.

The first space for manoeuvre was how the teachers in each school sought to authorise pupil voice through negotiation, something they uniformly had not engaged with in their previous practice. A second space for manoeuvre was through offering choices to girls to open up the range of possibilities of what physical education could be. As teachers and pupils coconstructed their local curricula, a third space for manoeuvre was the class environment, where girls felt they could trust their peers and teacher not to judge them as they engaged in the embodied practice of physical education. A fourth space for manoeuvre that emerged was teachers being challenged to re-think 'structure' within their curricula, given their attempts to negotiate the timetabling regime of the traditional multi-activity curriculum.

\section{'It wasn't something I would do naturally': Negotiation and authorising pupil voice}

An integral aspect of the co-construction of the curriculum that lies at the heart of an activist approach was the authorising of pupil voice (Oliver \& Kirk, 2015). Cook-Sather (2002) explains that this process involves a reconfiguration of the power relationships between teacher and pupils. As such, this was something neither the teachers nor their pupils 'would do naturally'. In this context, one of the teachers talked about her '50-50' relationship with her pupils:

My part of it, my $50 \%$, needs to be I need to be more aware of what's going on, I said, but then your $50 \%$ is tell me, because I think I've turned my back and then all this goes on in the background, so if you don't tell me then I can't act on it. So it's just been negotiation ever since. (Liana, School 1, January Workshop [JWS])

This 50-50 scenario not only required give and take between the teachers and their pupils, but also meant that both parties were accountable to each other in ways that clearly show teachers listening to respond. As Liana commented, 'The pupils will trust you and then you act on all of that'. (JWS)

Negotiation also featured in some of the other schools and teachers and pupils found themselves in discussion over a myriad of issues, at class level and as individuals. A prominent issue was girls' concerns about the time allowed for changing at the beginning and end of lessons:

They were talking about the changing thing and how long they get to change at both ends so I said well if you change quickly to get into the gym we can get started then I'll maybe extend your changing time at the end, because that's what they said, they were getting sweaty, trying to put tights, it's gross. So I said ok there's our negotiation. (Jess, School 3, JWS)

The girls in all four schools typically had strong feelings about changing time. As one girl commented, not without a sense of injustice, about a teacher who was not part of the project:

Pupil: She disnae gi'e us enough time to get changed. 
Kim: Not enough time to change.

Pupil: We're meant to get six minutes but then she's says we need to tidy up, she says she'll gi'e us eleven minutes to tidy up and get changed, but she disnae, she gi' es us six minutes to get tidied up and changed, and blames it on us. (Interview 2 School 2, $\operatorname{Jan} 16)^{1}$

Negotiation clearly required give and take by both teachers and pupils. But as Laura explains, this was far from straightforward since different parties had different interests at play. While Jess could empathise with her pupils over putting on tights following a lesson when they had been sweating, Laura felt that increased changing time and the negotiation to arrive at a compromise put serious pressure on time to be physically active in a lesson:

Because you're so used to it being a time frame that you have to get through certain things and really conscious of that, and then sometimes there's bits of the lesson, they take a long time getting changed. Like how much of the lesson are they actually active with, so the more you negotiate and slow things down at the start, you know your job as a PE teacher is to have them moving and how much of that do you give over (...) it wasn't something I would do naturally. (Laura, School 2, JWS)

Laura went on to say that the girls needed to learn to communicate, 'it's the culture, they're not used to being heard so they need to be asked first'. Jess made a similar observation with her comment, 'I don't think they got the chance to speak before'. She added that the quieter pupils in her class had shown the most notable change in terms of having the confidence to contribute to negotiations over their physical education programme:

When I did (..) the questionnaires with the girls at the end, things came out like, 'my voice is being heard', 'the others are listening to me' and 'I'm happy to speak out' and I thought ... now that they have the voice they're using it. (School 3, May Workshop [MWS])

Authorising pupil voice in order that teachers could listen and respond to girls was then not something that happened automatically, and the teachers recognised this was a learning process, for some girls more than others. This was not just a matter of pupils interacting with their teachers, but also the girls interacting with each other. As Kate noted:

Interacting with each other was definitely a challenge for them, I think as well taking ownership of their curriculum was a challenge for some of them, not all of them in the class, but the quieter ones. (School 4, MWS)

Despite their unfamiliarity with this form of communication over pedagogy, the teachers and their pupils began to feel more comfortable within this space. When we spoke with the girls from one of Kate's classes during the thematic unit in May, they had developed a chant or mantra, 'Go for it Girl!', in order to motivate each other in the class to try harder. In conversation with Kim, the girls said:

Pupil 1: Like to be more motivated cos we made this class mantra thing GFG which stands of 'Go For it Girl!'.

\footnotetext{
${ }^{1}$ In one school pupils spoke with a strong Glaswegian dialect. We transcribed the interviews as they sounded to remain as close as possible to some of the unique expressive qualities of this dialect.
} 
Kim: Oh cool, I love that.

Pupil 1: So like when we were running we would shout it to make our team work harder.

Pupil 2: To make the team motivated.

Kim: And do you think it worked? [Group Yes].

Kim: How come.

Pupil 2: Cos like see when you are at the back and because we are all supporting you can run really fast, so the other class would feel quite....

Kim: Oh right, so you're yelling, you're chanting the motto.

Pupil 2: I was going to say other classes came up to us, what are you shouting? and we're like that's our class mantra. (Pupils, May Focus Group, School 4)

Kate explained that the space that was opened up through the need for teachers and pupils to communicate differently during the process of co-constructing their programme was for her a main beneficial outcome for the pupils. Through negotiation and the conversations it involved:

They've learned how to build relationships and how to communicate with other people you might not necessarily know. I think as well they've quite enjoyed the responsibility of, responsibility first of all speaking in the class and having their opinions heard, but then responsibility as well of maybe having to lead a warm-up or organise equipment whatever it might be, so I think they've learned that throughout the block. (School 4, MWS)

'I think it took them a while to realise they could choose anything': Providing choice and variety, opening up the universe of possibilities

In our experience, teachers unfamiliar with activist work often misunderstand offering girls choice as 'letting pupils do whatever they want'. This is not how the process of providing choice and variety worked in the project schools. Negotiation between the teacher and class and among the girls themselves was central to providing choice and variety, and was a space for manoeuvre that both teachers and girls found empowering. Kate describes the beginning of the process in her school.

Originally we had about 20 activities on the board and we sort of crossed out the ones we already did and we were left with maybe 10 at the end. And there were some we couldn't do, you know the girls were really keen to do trampolining, but we don't have trampolines (...) the rest of them, I think it took them a while to realise they could choose anything, I think that was the problem to begin with, they didn't realise they could do things like yoga or boxercise until I gave them a wee example of you know what about Zumba? and all of a sudden it was what about boxercise? you know it took them a while to get into that. (Kate, School 4, JWS)

The girls strongly endorsed variety, with some noting that 'it's like a different thing every week, so it's more exciting as well'. (Pupil, School 4, January Focus Group [JFG]) At the same time one girl commented on a potential downside to variety, saying that 'we're just doing like a different thing every week, then we can't improve on that'. (Pupil, School 4, JFG) 
The purpose of sampling activities during $\mathrm{BtF}$ is to open up the range of possibilities for girls of what physical education can be, beyond the familiar and regular activities they experience within more traditional programmes. However, both the teachers and the girls recognised that this could be challenging. One girl said, 'Since we've started doing the new things, people have been wanting to try but like not always in their comfort zone'. (Pupil, School 1, JWS), while teacher-researcher Cara noted that, 'sometimes they are scared to do new activities'. (School 2, JWS) Some 'taster' activities did broaden girls' awareness of what is possible in physical education, though not always in ways they had anticipated, as Kate noted:

We did a spin class which I think they regretted twenty minutes into it (...) I don't think they realised how difficult it was going to be and they just thought they were going for a leisurely cycle on a bike and then quickly realised that wasn't what it was. (Kate, School 4, JWS)

While there were similarities in the teachers' work around choice and variety, each teacher and her class approached the task of developing and implementing a thematic unit differently during the second phase of the project, consistent with the idea of a pedagogical model as a design specification for the creation of local curricula. For example, Cara asked the girls what they wanted to know more about, and they came up with how to sleep better, to cope with stress, and to be more active. They then selected a theme of learning strategies to be more active in four spaces in their daily lives: at school, home, a sports club and out of doors. Cara organised activities that the girls could do in each of these spaces. Her intention for her pupils was:

Cara: How to improve something, something that they could do on a daily basis either when they were in school, so they were in school and I just wanted them to learn what they did at school that was helping them be active.

Kim: So you wanted them to identify where they were being active in these four spaces or were you wanting to...?

Cara: And try different things out to see what they liked in those four spaces. (School 2, MWS)

Jess wanted to tie her theme into the 'personal qualities' aspect of CfE since she noted that cooperation came up regularly among the girls when they were discussing what they would like to learn more about, and so teamwork was adopted as the theme. A variety of activities was undertaken, including some new games such as lacrosse and soccer, as well as rounders, orienteering in the local park, and fitness activities in the fitness suite when the weather was wet. Jess picked up on Cara's idea of different spaces from the project social media site, and noted her pupils:

Kept saying they wanted to go out and do things out-with school but were limited to one period. So I then said well I took on Cara's theme that you went out to the park and did orienteering. I got them to work in pairs, I thought you're getting to go out, we're very limited to where we're going, so we're going to go and do this in the park, so you can work on relationship and work just in pairs. (School 3, MWS)

Jess reported that some of her pupils, particularly from Muslim backgrounds, had few opportunities to be active outside of their homes and the school, so working in pairs developed the theme of teamwork while provide support in an unfamiliar outdoor situation. 
Liana's class focused their work around fitness. Activities included running, metafit and yoga, but also basketball, where games were conditioned to include fitness activities (e.g. run the length of the gym when a basket was scored), and information about heart-rate and exercise, training zones and other fitness-related knowledge. Liana commented:

I'm not sure how much fitness they really developed, but they engaged in it, they quite enjoyed that block and they quite liked trying out yoga, metafit, new things. But as you found out when you were out the other day (speaking to Kim and Cara), I don't really think it was the fitness side of things that was the focus for them, it was the class environment and how they developed group work. (School 1, MWS)

While fitness was ostensibly the theme, Liana felt the girls themselves were very focused on maintaining the good working relationships they developed in the BtF phase, and were concerned with respect, cooperation and teamwork. The pupils valued highly having a say in what activities they were experiencing in physical education:

Pupil: She's (the teacher) always told us you do it, it's your choice, like one of the girls $\mathrm{C}$ it's very much our decision of what we're going to do in PE, which is good, I like that. (Pupil, School 1, MFG)

The opportunity for classes to have a say in the activities that made up their physical education programme, and to sample novel activities, was an important new space for the participants in the project. In a recent study, Mitchell, Gray and Inchley (2015) reported that choice was a motivating factor for girls in a school-based physical activity programme. The novelty factor was in itself attractive for some pupils. But equally important, as the teachers comments show, was the processes of communication that were required to arrive at agreement amongst the class that everyone would try hard in all activities chosen, even those individuals hadn't voted for. We can see too in the examples provided that pupils and their teachers in each of the schools opted for different themes around which to organise their physical education experiences, illustrating the space for manoeuvre to accommodate local preferences and perceptions of need.

Not everyone agreed that choice worked for them and all new activities were interesting. While yoga was a well-received novel activity in some schools, some pupils from School 2 are discussing their discomfort in a yoga class taken by a teacher who was not participating in the project:

Pupil 1: No I think the maist boring thing was yoga.

Pupil 2: Naw cos it was awkward it was Miss G

Pupil 3: Aye and your bellies are hanging oot an aw that.

Pupil 2: And her feet was oot.

Pupil 1: Aye.

Pupil 4: I was aff that day thank god!

Pupil 2: Naw, even oor bellies were hanging oot cos like see when you done, like that mad thing we done when oor bums are up in the air and our tops would go up, you could see oor bellies and that's not a good sight.

Pupil 3: I felt uncomfortable daeing that and she was going 'good girl, good girl'. (Pupils, School 2, MFG) 
As this example suggests, even in a single-sex environment, some activities were a source of embarrassment for some girls, illustrating the embodied nature of physical education as a curriculum topic and the discomfort of public exposure. As such, a third space for manoeuvre was the creation of an environment of trust and care.

\section{'I feel more comfortable': Creating an environment of trust and care}

The environment of the class was of crucial importance for girls' willingness to engage in physical education activities. There were at least two key aspects to this space for manoeuvre for the teachers and their pupils, single-sex lessons, and not being judged. Both were important to developing trust and care and to girls feeling comfortable in a physical education context where their actions always take place publically.

Single-sex versus co-educational classes has been a controversial and unresolved issue in physical education (Flintoff \& Scraton, 2006). In this activist project, single-sex lessons created a space for manoeuvre for the teachers and their pupils in terms of the kinds of pedagogies of embodiment that could be practiced. Some of the girls who experienced physical education most often in a co-educational class were particularly vocal about their preference for the single-sex lessons:

Pupil 1: I feel more comfortable.

Pupil 2: It's mair fun.

Kim: You're more comfortable, why are you more comfortable?

Pupil 1: Because it's all lassies an' if you dae something in front of boys they just laugh at ye $(\ldots)$

Pupil 3: I think the boys could just be just a wee bit mair supportive.

Pupil 1: Supportive!? boys in this school being supportive!?

Pupil 3: Aye exactly! (Kim and Pupils, School 2, JFG)

Being laughed at by boys was clearly a common experience for these girls. Unsurprisingly, the issue of being forced to take part in physical activities in a co-educational context where ridicule from boys, and particular boys, was a certain outcome, evoked strong emotions:

Pupil 1: I hate getting forced tae dae stuff, made dae stuff in front of people.

Kim: You don't like doing things in front of people?

Pupil 1: Depends who, this class I'm awright wi'. (...)

Kim: So there's just things you prefer.

Pupil 1: No, like certain people I'd dae it in front, stuff in front of like everybody in this class, but see when it comes to B I don't dae it.

Pupil 2: B_ an' that, they just laugh at you when you do anything. (Kim and Pupils, School 2, JFG)

The language used by this girl, the words 'hate' and 'forced' for example, are strongly and justifiably emotive given the embodied nature of the activities involved. The single-sex environment on the other hand is clearly tolerable and acceptable.

Even for the girls in the girls-only school, their recollections of physical education in coeducational settings, for example in their primary school days, evoked explicit comment:

Pupil 1: We all used to be with boys. 
Kim: You all used to be with the boys and do you notice the differences between an allboys.

Pupils together: Oh Yes!

Kim: What are some of these differences?

Pupil 1: You're a lot comfortable and more like enthusiastic.

Pupil 2: Yeah you're willing to try because you know no one will make fun of you.

Kim: Oh, ok so you were made fun of by the boys. [Group agreement, Yes].

Pupil 3: And in the mixed school the boys used to do all the sports and they tell us you can't do that. (Kim and Pupils, School 3, JWS)

The pupils in the girls-only school experienced ridicule at the hands of boys in co-ed classes, but boys also told them they were unable to participate competently in some activities because they were girls. In an interview with another group of girls from the same girls-only school, it is clear that the single-sex class created for the girls a space in which their participation, enthusiasm and engagement was possible, in contrast to their co-educational experience:

Pupil 1: I think there is a difference here though because we're an all-girls school and I know in front of a boy I wouldn't want to do those, you don't want to push yourselves to do these silly things as we going look a bit more.... That's why we feel so comfortable with each other.

Kim: Just because it's an all-girls setting?

Pupil 2: I think it would be completely different if there was boys involved. (Kim and Pupils, School 3, JFG)

Physical education requires pupils to engage with its physical activity subject matter in what is essentially a 'public space'. As such, for pupils who have low perceived competence in physical activity, physical education lessons can be stressful experiences (Evans, Davies \& Wright, 2004). Within this single-sex setting and across the four schools, the girls articulated clearly and explicitly the importance of confidence and trust that they won't be judged in this public space:

Pupil 1: You are more confident around the people in your class, like you don't feel like they're going to judge you all the time, like make comments about you and all that. Pupil 2: It's cos like before it, you felt like everybody sort of constantly making a judgement on you or saying stuff about you, but now it's just like you can get on with it without having to worry. (Pupils, School 1, JFG)

Laura understood that some of her pupils' aggressive behaviour was actually the product of lack of confidence and fear, of being scared that they were going to fail and be shown up, and that this was a barrier to participation and putting in an effort:

A lot of them (girls) were not confident at all so their lack of engagement was just they didn't want to fail, literally they didn't want to do something bad or been shown up so they didn't want to try therefore it's a big barrier to participation for a lot of them. And some of them, they are defensive and they come across as very aggressive and bolshie which gets your back up and seeing behind that is a wee scared girl. (Laura, School 2, Individual Interview, December 2015) 
The activist work addressed this issue of the class environment during BtF through explicit conversations between teachers and pupils of their treatment of others and the creation of class rules that everyone agreed to follow (Kirk et al., 2016a). By the end of BtF this fearful environment in physical education had for some pupils changed:

Pupil: As a group we would not be afraid to embarrass ourselves, just for show like, we just try it, we're not going to make fun of each other, like we've to do something it's like you might look a bit silly doing or you can't do it or you're struggling to do it. It's just you have to try something like make sure you can or can't. (Pupil, School 3, JFG)

Securing a comfortable and safe environment is a considerable achievement since, as we can see in the girls' comments, the explicit display of the body is such a pervasive characteristic of physical education. While this trusting environment was evident in all schools, its sustained achievement could not be taken for granted, as these girls understood when they were asked what would make participation possible for them:

Pupil 1: Stop making fun of everybody.

Kim: Stop making fun of everybody, ok.

Pupil 2: Don't laugh at people that run or something.

Kim: Don't laugh at people in the way they do things, ok.

Pupil 3: Don't judge people.

Pupil 1: Like 'Hannah', she judges everybody.

Pupil 4 ('Hannah'): No I don't! I love everybody.

Kim: How many of you judge each other in terms of the way you do it?

Pupil 1: Don't even say you don't because you dae, you an'aw.

Kim: Why do you think you do that?

Pupil 1: Cos we're lassies, aw lassies dae it. (Kim and Pupils, School 2, JFG)

This somewhat fatalistic and deterministic observation that they judge each other 'cos we're lassies', whether correct or not, starkly illustrates the challenge of establishing an environment in which girls are able to trust each other not to judge as they engage in physical education activities, and the extent of the achievement when they do.

Feeling more comfortable in physical education involved the implementation of various pedagogies of embodiment that improved girls' willingness to engage in activities and indeed their preparedness to fail and not be laughed at or feel humiliated. The single-sex classes were spaces for manoeuvre for teachers and their pupils in order to co-construct an appropriate class environment.

'The plan has to be relaxed, a bit more fluid so you can respond to what exactly is happening': Rethinking structure

As we previously noted, a dominant traditional form of physical education is the multiactivity programme. In addition to a content focus of mainly games and sports and the teaching of sports-techniques, the structure of this approach usually coordinates the timetable and facilities in short blocks of lessons which change on a regular basis (Kirk, 2010). When multiple classes attend the physical education department, activities are often determined by the available facilities such as the games hall, playing fields, fitness room and swimming pool. This 'structure' for organising physical education programmes in schools is widespread and deeply embedded in thinking about the curriculum. 
A major challenge the teachers encountered in this project, then, was what they perceived initially to be a lack of structure to their activist teaching as they implemented the thematic unit during phase two. Kate, for instance, identified the variety of activities as a reason for the lack of structure, something that made her uncomfortable:

Through the variety, I found at times I didn't feel as though I had a proper structure to what I was doing. I felt as if I was maybe going from lesson to lesson, and I don't know if the girls felt that way and I think just for me I was saying this to you yesterday. I'm just used to having a plan and I know what's going to happen, whereas with this project it changed all the time, so I felt maybe a bit uncomfortable with it to be honest. (School 4, MWS)

Jess added that more structure was necessary if other staff in her school were going to be able to use this approach:

Have more of a structure for a start, because obviously we've been working through it, now we know what it is, we can actually now make a structure and then I can say to staff, this is what you're going to do these weeks. (School 3, MWS)

The teachers' perceptions of a lack of structure in the thematic units had a number of consequences. Some of these were very practical, such as what kit pupils should bring for their physical education lessons on any given day. Laura explained that for her being studentcentred and listening in order to respond to her pupils meant that her plans had to be adaptable and flexible and less traditionally structured than formerly:

I think giving them the choice or speaking to them at the start and explain things so that (...) came around that naturally. I think just even in the curriculum for excellence, you know, (I'm) well versed in that at the moment. Probably it's the action for them, react, listening and responding, is a constant on-going thing throughout and that means sometimes your structure is altered slightly because you are going with, the creating the plan has to be relaxed, a bit more fluid so you can respond to what exactly is happening. (School 1, MWS)

Both Cara and Kate had clear written plans for their thematic unit, with specific objectives for lessons. For example, Cara made strategies to improve wellbeing at home the focus of lessons 2 to 4; at school for 5 to 7; at a sports club for 8 and 9; and outdoors for 10 to 12 (Cara's written plan). Kate focused on the contribution of football to health and well-being in lessons 2 to 4; pupils exploring their limits in lessons 5 to 7; understanding how girls and women are portrayed in the media in 8 to 9; and learning strategies to improve well-being at home in 10 to 13 (Kate's written plan). Despite these clear plans on paper, implementation for Cara was more demanding than traditional units:

Thinking about different content all the time was hard because I'm used to teaching basketball and volleyball and badminton and I have that content knowledge, but thinking of something different still going with the theme was difficult, just planning it. (School 2, MWS)

The teachers felt that structure was necessary for them to plan and for the pupils to know what kit to bring to school, though they also understood that variety of activities and fluidity 
in delivering plans were important feature of an activist approach. As the discussion developed at the May Workshop, Kim explained how she uses structure in a thematic unit. Responding to this explanation, Cara said:

I guess the way to maybe look at it and you can tell me if I'm wrong here, if you look at the Significant Aspects (of Learning, CfE) and you say ok we're going to cover problem solving....

Kim: Team working, co-operation...

Cara: Decision making, whatever, how we get there it doesn't matter, some might get there by doing basketball because that's the unit they decided to cover, one thing, but you can get there doing a variety of different activities and that's kind of the way I looked at it. (Cara, MWS)

Structure, or perceived lack thereof, was a challenging space for manoeuvre for the teachers in relation to creating and implementing an activist thematic unit. The teachers had to learn new ways of thinking about structure that moved beyond fixed articulations of timetable, facility availability and lesson content. CfE promotes a conceptual approach to planning in physical education, but nevertheless the teachers' prior experiences of structure were centred mainly on the short unit of physical activities, where learning progression was based on the development of sports and games techniques. Working thematically within an activist approach challenged this multi-activity programme-based view of structure, and represented an important space for the teachers to negotiate as they pushed up against the status quo of traditional physical education.

\section{Conclusion}

Our purpose in this paper was to examine an approach to curriculum making that seeks to balance the contributions of researchers as agents external to the school, and teachers and pupils as local agents. We drew on a Stenhousean (1975) concept of 'curriculum as specification' to explain that pedagogical models in physical education are design specifications for the development of programmes in schools that meet local needs and priorities. We provided some illustrations of the co-construction of a prototype activist pedagogical model as the teachers and pupils implemented it and learned to use it, with support from the research team. Four spaces for manoeuvre emerged from this work with an activist model: new forms of communication based on authorising pupil voice; offering choices and opening up learning possibilities; the co-construction of a safe class environment; and opportunities to rethink traditional structures based on the multi-activity curriculum form.

These data have led us to five conclusions. First, a broad and bold curriculum type such as $\mathrm{CfE}$ is able to accommodate a range of approaches to physical education, including an activist, student-centred pedagogical model. Second, within this context, an activist pedagogical model provided teachers and pupils with spaces to explore alternative practices to traditional forms of physical education that were well-received by most pupils and their teachers (Kirk, 2016a and 2016b). Third, the prototype model worked as a design specification and facilitated the development of local programmes with reasonable fidelity to the critical elements. Fourth, while teacher agency is clearly complex, the five teachers in this study appear to have begun to learn how to use an activist approach, though their professional learning varied since, among other things, it was strongly influenced by their local school contexts (Kirk, 2017). Finally, we think there is evidence to show that some girls with support from their teachers and peers had begun to identify, name and critique the barriers to their enjoyment of and participation in physical education. 
Consistent with Tinning's (2010) 'modest pedagogy', and following Stenhouse (1975), we think the prototype pedagogical model survives this first critical, though small-scale, test of practice. We think it has the potential, with broad and bold curriculum types, to provide one means of balancing external agency and local agency through the mechanism of the pedagogical model as a design specification. While the two phases of the activist approach appear to us to be appropriate, the thematic phase was challenging for the teachers since it did not fit easily within traditional notions of curriculum structure. More and better resources for teachers in terms of ideas for addressing this challenge, many of them generated by this project, would be important features of future activist pedagogical work. Moreover, while the pupils in general seemed to benefit from this activist approach, we think a more specific focus on learning is warranted in future research, particularly in terms of the attributes that are likely to lead to sustained and sustainable engagement in physical activity such as motivation, resilience, perceived competence and enjoyment. 


\section{Acknowledgement}

We wish like to thank Maureen McKenna, Executive Director of Education at Glasgow City Council, and the Head Teachers of the four schools for giving permission for this project to take place.

\section{References}

Bailey, R., Armour, K., Kirk, D., Jess, M., Pickup, I., \& Sandford, R. (2009). The educational benefits claimed for physical education and school sport: an academic review. Research Papers in Education, 24(1), 1-27.

Casey, A. (2014). Models-based practice: great white hope or white elephant? Physical Education and Sport Pedagogy, 19 (1), 18-34.

Cook-Sather, A. (2002). Authorizing students' perspectives: Toward trust, dialogue, and change in education. Educational Researcher, 3(4), 3-14.

Enright, E., \& O’Sullivan, M. (2010). 'Can I do it in my pyjamas?' Negotiating a physical education curriculum with teenage girls. European Physical Education Review, 16(3), 203222.

Evans, J., Davies, B. \& Wright, J. (Eds.). (2004). Body knowledge and control: Studies in the sociology of physical education and health. London: Routledge.

Flintoff, A. \& Scraton, S. (2006). Girls and physical education. In D. Kirk, D. Macdonald, and M. O’Sullivan, M. (Eds.), Handbook of Physical Education (pp. 767-783). London: Sage.

Haerens, L., Kirk, D., Cardon, G., \& Bourdeauhuji, I. (2011). The development of a pedagogical model for Health-Based Physical Education. Quest, 63, 321-338.

Jewett, A., Bain, L.L. \& Ennis, C.D. (1995). The curriculum process in physical education (2nd ed). Dubuque: Brown.

Johnson, S., Gray, S., \& Horrell, A. (2013). 'I want to look like that': healthism, the ideal body and physical education in a Scottish secondary school. Discourse: Studies in the Cultural Politics of Education, 34(3), 457-473.

Kirk, D. (2013). Educational value and Models-Based Practice in Physical Education. Educational Philosophy and Theory, 45(9), 973-986.

Kirk, D. (2010). Physical Education Futures. London: Routledge.

Kirk, D., Lamb, CA., Oliver, KL. with Ewing-Day, R., Fleming, C., Loch, A. \& Smedley, V. (2017). School-based teacher professional learning of an Activist Approach to working with adolescent girls in physical education. Paper presented to the Instruction and Learning in Physical Education SIG of the American Educational Research Association, San Antonio.

Kirk, D., Lamb, CA, Oliver, KL with Ewing-Day, R., Fleming, C., Loch, A. \& Smedley, V. (2016a). Building the Foundation for an activist approach to working with adolescent girls in 
physical education, Paper presented to the British Educational Research Association Annual Conference. University of Leeds, September.

Kirk, D., Lamb, CA, Oliver, KL with Ewing-Day, R., Fleming, C., Loch, A. \& Smedley, V. (2016b). Developing a thematic unit for an activist approach to working with adolescent girls in physical education. Paper presented to the Annual Conference of the Scottish Educational Research Association. Dundee, November.

Kirk, D. and Oliver, KL. (2014). La misma historia de siempre: reproducción y reciclaje del discurso dominante en la investigación sobre la educación física de las chicas/ The same old story: the reproduction and recycling of a dominant narrative in research on physical education for girls. Apunts. Educación Física y Deportes, 116, 2. trimestre (abril-junio), 7-22.

Kirk, D. \& Macdonald, D. (2001). Teacher voice and ownership of curriculum change. Journal of Curriculum Studies, 33(5), 551-567.

Lund, J., \& Tannehill, D. (2005). Standards-based physical education curriculum development. Sudbury, MA: Jones and Bartlett Publishers.

Macdonald, D. (2003). Curriculum change and the post-modern world: is the school curriculum reform movement an anachronism? Journal of Curriculum Studies, 35(2), 139149.

Metzler, M. (2011). Instructional models for physical education ( $3^{\text {rd }}$ ed.). Arizona: Holcomb Hathway.

Mitchell, F., Gray, S., \& Inchley, J. (2015). 'This choice thing really works ...' changes in experiences and engagement of adolescent girls in physical education classes, during a school-based physical activity programme. Physical Education and Sport Pedagogy, 20(6), 593-611.

Mitchell, F., Inchley, J., Fleming, J., \& Currie, C. (2015). A socio-ecological approach to understanding adolescent girls' engagement and experiences in the PE environment: A case study design. Graduate Journal of Sport, Exercise \& Physical Education Research, 3, 44-62.

Niven, A., Henretty, J., and Fawkner, S. (2014). 'It's too crowded': A qualitative study of the physical environment factors that adolescent girls perceive to be important and influential on their PE experience. European Physical Education Review, 20(3), 335-348.

Noy, C. (2008). Sampling knowledge: the hermeneutics of snowball sampling in qualitative research. International Journal of Social Research Methodology, 11(4), 327-344.

OECD (2015) Improving schools in Scotland: An OECD perspective. Paris: OECD

Okely, AD., Lubans, DR., Morgan, PJ, Cotton, W., Peralta, L., Miller, J., Batterham, M. \& Janssen, X. (2017). Promoting physical activity among adolescent girls: the Girls in Sport group randomized trial. International Journal of Behavioral Nutrition and Physical Activity, $14: 81,2-13$. 
Oliver, KL. \& Kirk, D. (2015). Girls, gender and physical education: An activist approach. London: Routledge.

Oliver, KL. \& Oesterreich, HA., et al. (2013). Student-centred inquiry as curriculum as a model for field-based teacher education. Journal of Curriculum Studies, 45, 394-417.

Oliver, K. L., Hamzeh, M. \& McCaughtry. N. (2009). 'Girly girls can play games/Las niñas pueden jugar tambien:' Co-creating a curriculum of possibilities with 5th grade girls. Journal of Teaching in Physical Education, 28(1), 90-110.

Priestley, M. (2010). Curriculum for Excellence: transformational change or business as usual? Scottish Educational Review, 42(1), 23-36.

Priestley, M., Biesta, G., \& Robinson, S. (2015). Teacher agency: An ecological approach. London: Bloomsbury.

Priestley, M., Edwards, R., Miller, K., \& Priestley, A. (2012). Teacher agency in curriculummaking: Agents of change and spaces for manoeuvre. Curriculum Inquiry, 42(2), 191-214.

Scottish Health Survey. (2016). http://www.gov.scot/Resource/0052/00525472.pdf

Siedentop, D. (1996). Valuing the physically active life: Contemporary and future directions. Quest, 48(3), 266-274.

Siedentop, D. (2002). Content knowledge for physical education. Journal of Teaching in Physical Education, 21: 368-377.

Stenhouse, L. (1975). An introduction to curriculum research and development. Heinemann: London.

Taylor, J., Hughes, A. \& Koufaki, P. (2013). The impact of community-based physical activity projects on girls' and young women's engagement in physical activity: findings from an evaluation of the 'Girls on the Move' programme. Managing Leisure, 18, 46-60.

Thorburn, M. \& Gray, S. (2010). Physical Education: Picking up the baton. Edinburgh: Dunedin.

Thorburn, M. (Ed.) (2018). Wellbeing, education and contemporary schooling. London: Routledge.

Tinning, R. (2010). Pedagogy and human movement: Theory, practice and research. London: Routledge.

UNESCO/ IBE (2013). Glossary of curriculum terminology. Geneva: UNESCO.

Vertinsky, P. (1992). Reclaiming space, revisioning the body: The quest for gender-sensitive physical education. Quest, 44: 373-396 